\section{Readability Calculation by Microcomputer}

Tom Rich

Tom Rich is the Media Coordinator for ward Island.
Often when preparing scripts, support
materials and other materials for audiovisual programs, questions arise about the readability of the language. How do the writers level? Often materials seem to be prepare on the basis of intuition or experience. Certainly, changes are made after piloting, but
the changes are often superficial. Seldom are the changes are often superficial. Seldom are
alterations made in the language level of the

Readability formulas which could help to
determine the actual difficulty of the determine the actual difficulty of the language, often seem too complex and
cumbersome to calculate. Recently, however, microcomputers have been able to adapt the readability measures making them more useful to the curriculum expert and the audiovisual practioner. Microcomputers
seem to eliminate the tedium from the mathematics of readability evaluations. This article will describe a program
adapted from a longer adapted from a longer one described in an
article by Michael Schuyler, "A Readability article by Michael Schuyler, "A Readability
Formula Program for Use Microcomputers," in the March, 1982 Journal of Reading. It had been redesigned to run on a PET microcomputer. Because of memory limitations some of the features The original program have been eliminated and, if desired, a printer can be used for the final output.

Purpose

The program gives basic statistical
information on the sample passage including words, sentences, three-syllable words, syllables per 100 words and sentences per 100 readability are computed and the das for plotting a Fry Readability Graph is given. The passage to be evaluated can be an length but commonly passages of 100 word of material from a book, it is suggested you use several passages of approximately 100
words from various sections of the book. Methodology

A few comments must be made about how
the material to be evaluated should be entered. The first thing you will see on the screen is an abbreviated set of instructions. you to enter the name of the book or wall as you are evaluating and the number of lines
of text in the first section to be entered. After

of words or sentences in the passage to be evaluated as the program does that for you. Simply count the number of lines, as the pasar in the source material, in the fir bottom of the screen when you are ready to typing each, press the RETURN key. key may also be used. nter the text. You will enter it one line
time; a new line is indicated with mark. The lines correspond to the lines in 作 computer. Simply type the line in

dige of the screen is reached. The line ne screen. Don't worry about next lin eing broken up at the end of the line. cannot take up more than two lines on the computer screen. If it does, you will have break it into two parts.

Each line of text entered must end with (?) If the line in the source passagetion not correspond to the end of a sentence the pace after the last word and type a slas a l line cannot be broken wits at the a line cannot be broken with hyphens. a line, complete the word before addit the slash and hitting RETURN. different froping of the material is a litte punctuation at the end of the lines sentences, absolutely no punctuation may be used including commas, colons, semi-colon dashes, quotes or parentheses or any othe
symbol that is not a letter or a number the end of the sentence the normal punctuation is used. Note however, that you must leave a space between the last word and
the ending punctuation. The following the ending punctuation. The following space between the punctuation and the firss word of the sentence. In addition, the typing is done automatically in all capitals. You do
not have to use the shift key. Here is an example. Each line from the source material begins at a question mark RETURN

$?$ THIS IS SAMPLE TEXT .NOTE PERIOD NOT AFTER ? AND THE SLASH AT THE END OF THE LINE WHEN NOT A SENTENCE END then have completed hit RETURN is from the text. Before you do so, check the sline for errors and make sure it ends with corrections after hitting RETURN. The fina line of the passage must end with a period, question mark or exclamation mark. If you the upper right of the number Ded. This wil erase letters. To position the cursor to chan letters, the cursor controls next to the DEL

When you hit RETURN, there will be a slight pause as the line is evaluated by the ogram and then another question mark iill appear for the second line to be entered. an sentence must have normal punctuation the end - not a slash. You must also use
the number of lines which you specified in the beginning of the program. The computer will keep returning with question marks unWhen the last line has been entered the computer will automatically process the material and, after a slight pause, display the
results. At that time, you will have the opcosults. At that time, you will have the opsame text or ending. If you answer YES eprogram will again ask how many lines
text and display the question marks to enter the copy. This must be material from If you wish to switch to evaluating different materials, you should answer NO and start When you have completed the nu

assages you wish to evaluate in the parsplay the summary data table (See Figure 1). Tis is essentially the same as the one seen many passages have been evaluated and the total number of words, three syllable words, The rest of the data is averaged across all the

vords and sentences per 100 worls per 100 in plotting a Fry Readability Garaph (See
Figure 2). Enter the sentence data for the

FIGURE 1

*READABILITY*

FOCUS ON SCIENCE

TOTAL PASSAGES 1 THRU 10

1032 WORDS

3-SYLLABLE WORDS

SENTENCES

SYl.58 SYLABLES PER 100 WORDS

FOG READING LEVEL

FLESCH READING EASE

PLESCH GRADE LEVEL

FLESCH-KINCAID

COLEMAN

OR FRY, PLOT SYLLABLES PER 100 WORDS ON FRY GRAPH. graph on the vertical axis and enter the int where the two horizontal axis. The pry

paper copy of the final table. Answer YES to the question if you wish a printout an

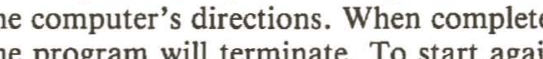
nd analyze material from another source, mply type RUN again. There is no need to

Program Output

On the printed output of a sample run 作 the passages can be of any length. The statistics include the sum total of words, sylables, sentences and three syllable or
longer words which are found in all the

The program counts the number of words 982 are all counted as one word each. I P.E.I. was entered with periods, the program
would count three sentences, one for each period, but only one word as no spaces ocA comma or other punctuation after would cause one extra letter to be added to the simply tells the computer end of sentence continues on the next line.

The program estimates the number of
yyllables by dividing the total number of letsyllables by dividing the total number of letresult to two places. The number of three checking for words with nine or more letter and three or more vowels.

A total of six formulas plus the Fry data ( entences and syllables per 100 words) are Flesch, Powers, ARI (Devereaux), Coleman,
and Flesch-Kincaid. Following is a brief overview of each adapted from Schuyler's ar etailed sources on readability is found in the Reference section

Fry

The index is derived by plotting the nd syllables per 100 words on a graph. provides an approximate grade level and reasons for the score. As a result, Fry scores
are particularly helpful in suggesting ways to increase readability and in understan why passages are rated as they are.

Fog

The formulas used in the Fog scores is as
follows: $4^{*}(\mathrm{~T} / \mathrm{W} * 100+\mathrm{W} / \mathrm{S})$ when equals three syllable words, W equals words, and $\mathrm{S}$ equals sentences. ed to the average sentence length. This is

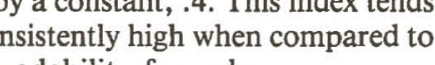
the other readability formulas.

Flesch

The formula for a Flesch count is as
follows: $206.835-.846 *^{*} \mathrm{~L} 3-1.015 *(\mathrm{~W} / \mathrm{S})$, when $L 3$ equals the syllables per 100 words, W equals words and $S$ equals sentences.
This formula does not yield a direct grade level but provides a reading ease score beteen 0 and 100 based on the number of syllables, words and sentences. A high score in ed an appoximate grade level from this. He ed an appoximate grade level from this. He
defines scores of $92-100$ as grade 4: $81-90$ as grade 5, and so on. No fractions of a grade Powers The formula for the Powers scores is as
follows: $-2.209+.0778^{*}(\mathrm{~W} / \mathrm{S})+.0455 *$ *
L3. when L equals syllables per 100 words, L3. when $L 3$ equals syllables per 100 words,
W equals words and $S$ equals sentences. Although Powers uses the same variables stants and a different order of computation. The value derived relates directly to a grade lower than any of the others with the exception of ARI.

The ARI formula is as follows: $1.56 * \mathrm{WL}$ length and SL equals sentence length. This formula is the simpliest formula of the readability formulas given. Although it ly grades lower. Schuyler found that when the other formulas gave levels of from 12 to 14, the ARI formulas often gave levels of from 5 to 6

Flesch-Kincaid
The Flesch-Kincaid formula is computed as follows: $39 *(\mathrm{~W} / \mathrm{S})+11.8 *(\mathrm{Sy} / \mathrm{W})$ sentences and Sy equals syllables. This formula is a derivation of the Flesch formula which compute grade level direct-
ly. Unlike the Flesch scale, grade levels of less than four are also computed. For very simple material, negative values may be

The Coleman formula is as follows: $-27.4004 *$ Cloze $\%+23.06395$. In the Coleman formula Cloze\% equals $(141.8401$
$.21459^{*}\left(\mathrm{~L} / 1 / \mathrm{W}^{*} 100\right)+1.079812^{*}(\mathrm{~S} /$ L1 equals letters in the passage, $\mathrm{S}$ equals 
sentences and $\mathrm{W}$ equals words. syllables and correles letters rather than Fry but will also yield negative values for very easy material.

Sch of (1982) points out that although all of these readability indices have a very among the scores should not be surprising as they are all using the same data and many of the same variables. However, it should be pointed out that the ARI index, closely score lower than the others while the Fog in-
dex tends to score consistently higher than readability is sample size. There is some
evidence (Coke and Rothkopf, 1970) to indicate that more than 10 per cent of the
words in the material analyzed may have to we sampled in order to reduce the possibility of error to or acceptable level. It does tend to grades very highly with Fry. equally valid. A high degree of cor not be A critical element in the evaluation of
readabilyty is sample size. imitations

This version of the program has certain or instance the Dale formula which necesitates a 3,000 word list for comparisons, is the Those who a int being considered. ula or the Apple version of the program Ilete program listing.

I the program

References

Coleman, M. and Liau, T.L. A computer
readability formula designed fo readability formula designed for
machine scoring. Journal of Applied
Psychology. 1975, 60, 282-284. odification are currently bugh a means of

Coke, E.U. and Rothkopf, E.Z. Note on imple algorithm for a computer pro. Applied Psychology. 1970, 54, 208-20 sch, R.F. A readability yardstick. Jou nal of Applied Psychology. 1948, 32, ry, E. Fry's readability graph: Clarific ions, validity, and extension to level 17
Journal of Reading. $1977,21,242-252$ Py, W.B. How to measure readability
Philadelphia, Pa.: Dorrance and Phils.

Kincaid, J. Derivation of new readability formulas (Automated readability ind
fog count, and Flesch reading ease for mulas) for navy enlisted personnel. A Reproduction Service No. ED 108 134, chuyler, M.R. A readability formula program for use on microcomputer.
nal of Reading. 1982, 560-591.

Smith, E. A Devereaux readability inder J4, 289-303. Educational Research. 196

FIGURE 2
The Fry Readability Graph

\section{Directions}

Enter graph with average number of plotted will give you the approximate grat

the two lines intersect. Area where dot is (1977) in the Journal of Reading.
(1)

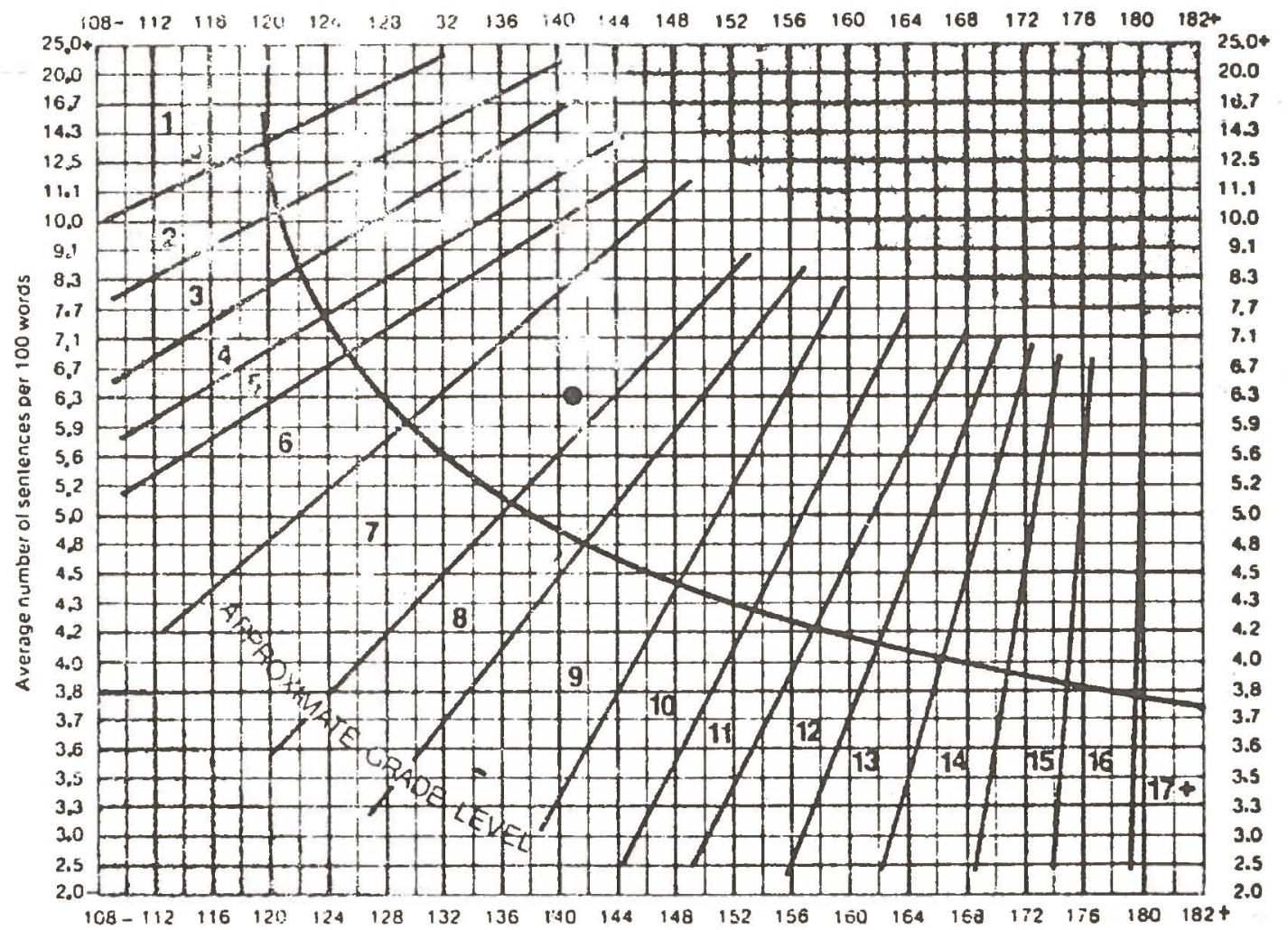

like the Arabs..."'?

enis Hlynka

the. Those of us in AMTEC have, of course been expecting and even predicting for some time. We always knew that our field would someday thrust itself to the forefro ever since Thomas Edison predicted for motion pictures a future ahead of its time:
Maybe I'm wrong, but I should say that in ten years textbooks as the principal medium of teaching will be as obsolete as the horses and carriages are
now... Visual education, the imparting of exact information through the $m$ course in all our schools.

(Colliers, Feb. 28, 1925, V 75, \#8.) by 1935 , nor for was wrong. It didn't happ or 1965 . It still hasn't happened Simila predictions were made for other media whic promised to revolutionize education: programmed instruction, television, games and of the promise.

And now the computer revolution is upon us, and somehow, this time, we have been caught standing What go by.

mplications for the computer/telecommunications revolution upon
AMTEC? It seems to me that AMTEC $h$ three obvious but equally possible alternatives. First, it can adapt immediately resolves, and come out as a major leader educational technology in Canada. Alternatively, AMTEC can maintain its rather low profile, status quo approach. Or, thir unnecessary in a world of media specialization, and in the words of the poet,
"... fold its tents like the Arabs And as silently steal away."

Many of us perhaps would

ject this latter option, but if wediately rein examining AMTEC's future, I believe tha we must allow all three options to stand very real and viable possibilities.
The fact is that the study of the tion society, far from being a timid field
seeking a home, has already been claimed and welcomed by more than one eager grou to futurists, have been by-passed. And, the fact is tha we are moving to more specialized interes groups.... a challenge which may be beyon AMTEC' 82 conference in Winntend more specific options are available: a distance education conference (ICCE);
children and television conference; a videoter

Denis Hlynka is an Associate Professor of Educational Media and Technology in the Faculty of Education at the University of
Manitoba. He is also the new edito of the anadian Journal of Education e, a vocational compu And if AMTEC doesn't survive A membership is prepared to support fully clearly defined set of objectives, we may inpoblems addressed here ae noted that the here are not uniquely ent rumors from the United States suggest chat AECT, a much larger and healthier pre Which leads us to the major concern of Journal of Educational Communication. Le us review what has been done so far.
First and most significant Lewis has taken our modest Media Message and given it a facelift coupled with a new name is a new philosophy. Media Message is now the Canadian Journal of Educational
Communication. Its functions have expanded considerably. CJEC presents readers with profiles of educational media and com-
munication technology happenings in Canada and elsewhere; it acts as the officia organ of AMTEC; and it provides a chanacademic papers at the cutting edge of our field.
Second, under the editorship of Richard
Lewis, the first four issues of Lewis, the first four issues of CJEC have
already appeared. Thus the first action steps have already been taken to give the journal a more significant role in AMTEC. Third, a new editor of CJEC is about to
take over It is always difficult to predict precisely what impact a new edit to predict policy might have. Nevertheless, we think we can give you some glimpses into what you might expect from CJEC for the next two years: Feature Articles. An attempt will be made mechanism for formal refereed papers as the backbone of the journal. The trend will be towards fewer but longer contributions within this section. AMTEC media organizations across the country. We hope to be able to profile such organizations on a regular basis within this column. happenings across the country is the goal for this column.

de. A review of significant curren documents from the Educational Resources be a regular feature. Bibliographies. This section will feature basic print and media bibliographies on subjects
of interest to educational technologists.
Fiction. This section is only in the experimen-
tal stages. Most media journals tend to be tal stages. Most media journals tend to be cognitive in approach and content. The premise of including a fiction section in this
journal is based upon the assumption that
there is indeed a body of work from the entertainment domin which approaches truth as a unique slice of life, a frozen moment in time. Should the concept be
workable, CJEC will begin modestly by 